Technological University Dublin

DÜBLIN

ARROW@TU Dublin

\title{
A Highly Efficient Ag-ZnO Photocatalyst: Synthesis, Properties, and Mechanism
}

\author{
Suresh Pillai \\ Technological University Dublin, suresh.pillai@tudublin.ie \\ Michael Seery \\ Technological University Dublin, michael.seery@tudublin.ie \\ Reenamole Georgekutty \\ Technological University Dublin, r.georgekutty@tudublin.ie
}

Follow this and additional works at: https://arrow.tudublin.ie/cenresart

\section{Recommended Citation}

Seery, M., Georgeknutty, R. \& Pillai, S. C. (2008) A Highly Efficient Ag-ZnO Photocatalyst: Synthesis, Properties and Mechanism. Journal of Physical Chemistry C, vol. 112 no. 35, 2008, 13563-13570. doi:10.1021/jp802729a

This Article is brought to you for free and open access by the Crest: Centre for Research in Engineering Surface Technology at ARROW@TU Dublin. It has been accepted for inclusion in Articles by an authorized administrator of ARROW@TU Dublin. For more information, please contact arrow.admin@tudublin.ie, aisling.coyne@tudublin.ie,gerard.connolly@tudublin.ie.

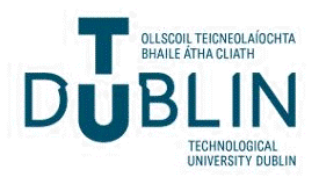




\section{Effect of Silver Modification on the Photocatalytic Activity of Nanocrystalline ZnO}

\begin{tabular}{|r|l|}
\hline Journal: & The Journal of Physical Chemistry \\
\hline Manuscript ID: & jp-2008-02729a.R1 \\
\hline Manuscript Type: & Article \\
\hline Author: & $\mathrm{n} / \mathrm{a}$ \\
\hline Complete List of Authors: & $\begin{array}{l}\text { Seery, Michael; Dublin Institute of Technology, School of Chemical } \\
\text { and Pharmaceutical Sciences } \\
\text { Georgekutty, Reenamole; Dublin Institute of Technology, School of } \\
\text { Chemical and Pharmaceutical Sciences } \\
\text { Pillai, Suresh; Dublin Institute of Technology, CREST }\end{array}$ \\
\hline
\end{tabular}

\section{S) ScholaroNE \\ Manuscript Central}




\title{
A Highly Efficient Ag-ZnO Photocatalyst: Synthesis, Properties and Mechanism
}

\author{
Reenamole Georgekutty, ${ }^{1,2}$ Michael K. Seery, ${ }^{1 *}$ Suresh C. Pillai, ${ }^{2} *$ \\ ${ }^{1}$ School of Chemical and Pharmaceutical Sciences, Dublin Institute of Technology, Kevin Street, Dublin \\ 8, Ireland. \\ ${ }^{2}$ Centre for Research in Engineering Surface Technology (CREST), FOCAS Institute, Dublin Institute of \\ Technology, Camden Row, Dublin 8, Ireland.
}

AUTHOR EMAIL ADDRESS (r.georgekutty@dit.ie, Michael.seery@dit.ie, suresh.pillai@dit.ie)

RECEIVED DATE (to be automatically inserted after your manuscript is accepted if required according to the journal that you are submitting your paper to)

TITLE RUNNING HEAD A Highly Efficient Ag-ZnO Photocatalyst

CORRESPONDING AUTHOR FOOTNOTE * michael.seery@dit.ie, suresh.pillai@ dit.ie

ABSTRACT: Highly photocatalytically active silver modified $\mathrm{ZnO}$ has been prepared and the effect of silver modification was studied. The structural and optical properties were characterised by XRD, FTIR, DSC, BET surface area, Raman, UV-Vis and photoluminescence spectroscopy. The photocatalytic activity of these materials was studied by analysing the degradation of an organic dye, rhodamine $6 \mathrm{G}$ (R6G), and it is found that $3 \mathrm{~mol} \%$ silver modified $\mathrm{ZnO}$ at $400{ }^{\circ} \mathrm{C}$ shows approximately four times higher rate of degradation than that of unmodified $\mathrm{ZnO}$ and a three times higher rate than that of commercial $\mathrm{TiO}_{2}$ photocatalyst standard Degussa P-25. It was also noted that the photocatalytic activity 
for the modified $\mathrm{ZnO}$ sample was five times higher than the unmodified sample using sunlight. The effect of silver in enhancing the photocatalytic activity has been studied by analysing the emission properties of both $\mathrm{ZnO}$ and silver modified $\mathrm{ZnO}$ in the presence (emission increases) and absence (emission decreases) of R6G. We attribute these observations to the extent of valence band hole production and the role of silver in trapping the conduction band (CB) electrons in the absence of R6G. In the presence of $\mathrm{R} 6 \mathrm{G}$, the dye preserves the $\mathrm{CB}$ electron population in the metal oxide, thus preserving and enhancing emission intensity. The sensitizing property of the dye and electron scavenging ability of silver together constitute to the interfacial charge transfer process in such a way to utilise the photoexcited electrons.

KEYWORDS; ZnO, silver modification, visible-light photocatalysis, mechanism.

\section{Introduction}

The application of semiconductors such as $\mathrm{ZnO}$ and $\mathrm{TiO}_{2}$ in the area of photocatalysis has grown considerably, primarily because of their physical and chemical stability, high oxidative capacity, low cost and ease of availability. ${ }^{1,2,3,4,5,6}$ Of the semiconducting materials, $\mathrm{ZnO}$ offers significant opportunity in providing electronic, photonic, and spin-based functionality (spintronics) because of its direct wide band gap (3.37 ev) and large exciton binding energy of $\sim 60 \mathrm{meV}$. This makes it worthy in the potential and established hi-tech applications such as ceramics, piezoelectric transducers, optical coatings, high speed and display devices, ${ }^{7,8,9,10}$ gas sensors, ${ }^{11}$ varistors, ${ }^{12,13}$ photocatalysts ${ }^{14}$ and photovoltaics. $^{15}$ Also the high chemical stability and low toxicity together make $\mathrm{ZnO}$ suitable for UV screening applications.

These semiconductors are well established and there has been considerable interest in their applications to the area of photocatalysis. ${ }^{16}$ Because of their wide band gap, they absorb mainly in the UV region. Numerous studies report an improvement of visible-light photocatalytic activity of metal oxide semiconductors by doping with cations, ${ }^{17}$ anions, ${ }^{18}$ metals ${ }^{19}$ and non-metals. ${ }^{20,21}$ There are also some reports of the detrimental effect of dopants in the photocatalytic activity. ${ }^{22}$ The photocatalytic activity of $\mathrm{ZnO}$ has been widely explored and reported. ${ }^{14,23}$ In terms of studying the mechanism of photocatalysis, 
$\mathrm{ZnO}$ offers some advantages over $\mathrm{TiO}_{2}$, primarily the fact that $\mathrm{ZnO}$ is quite strongly luminescent. This facilitates a study of the recombination of electron-hole pairs and hence a suitable probe in the study of highly active photocatalysts. The emission properties have also been used to sense the presence of organic molecules in its immediate vicinity. ${ }^{24}$

The modification of semiconductors with noble metals has attracted significant attention especially in heterogeneous photocatalysis. ${ }^{25,26}$ Incorporating silver in $\mathrm{ZnO}$ is now an exciting area in research for developing electronic applications. In addition, silver modification is found to be effective for the fabrication of $p$ - type $\mathrm{ZnO},{ }^{27}$ as the naturally occurring $\mathrm{ZnO}$ displays $n$ - type conductivity due to its native defects such as zinc interstitials and oxygen vacancies. The modification with silver has influenced the photocatalytic activity of nanocrystalline photocatalysts because of its optical and electronic properties. $^{28,29,30}$ In our previous study, we reported a significant enhancement in photocatalytic activity of $\mathrm{TiO}_{2}$ by modification with silver. ${ }^{31}$ Recently, Kamat and co-workers have studied the interfacial electron transfer process in silver modified $\mathrm{TiO}_{2}{ }^{32}$ Extensive research is underway to depict the exact role of silver in increasing the visible light response of metal oxides. Silver can trap the photogenerated electrons from semiconductor and allow the holes to form hydroxyl radicals which results in the degradation reaction of organic species present. Moreover, silver can enhance the photocatalytic activity by creating a local electric field and the optical vibration of surface plasmon in silver can make a reasonable enhancement in this electric field. ${ }^{30}$ The increased photocatalytic activity of silver modified $\mathrm{ZnO}$ is reportedly due to the change in the surface properties such as oxygen vacancies and crystal defects. ${ }^{33}$

Although there are reports about the effect of silver addition in the electric and optical properties of $\mathrm{ZnO}$ for electronic applications, ${ }^{34}$ to the best of our knowledge, there are no detailed studies on the effect of silver modification in $\mathrm{ZnO}$ based on various calcination temperatures. ${ }^{35}$ In this paper, we report a systematic study on the effect of silver modification in $\mathrm{ZnO}$ and consequent photocatalytic activity. The methodology of synthesis of our materials reported here is through a straight-forward non-aqueous 
route. The enhancement in photocatalytic activity due to the presence of silver is studied by characterisation of the materials and optimisation of the reaction conditions. A possible mechanism of photocatalysis is also been presented by analysing the effect of various amounts of silver in the emission properties of both $\mathrm{ZnO}$ and Rhodamine $6 \mathrm{G}$ dye.

\section{Experimental section}

\subsection{Materials}

Zinc acetate dihydrate (98\%), oxalic acid (97\%), silver nitrate (99\%) and ethanol were purchased from Aldrich and used as received. The dye used for the photocatalytic study (rhodamine 6G) was purchased from Eastman and was of analytical reagent grade and used without further purification. Double distilled water was used in all the experiments.

2.2 Preparation of $\mathrm{ZnO}$ powders: In a typical experiment, zinc acetate (10.98 $\mathrm{g}, 50 \mathrm{mM})$ was dissolved in ethanol $(500 \mathrm{~mL})$ at $60{ }^{\circ} \mathrm{C}$ and stirred for $30 \mathrm{~min}$. Oxalic acid $(12.55 \mathrm{~g}, 100 \mathrm{mM})$ dissolved in ethanol $(200 \mathrm{~mL})$ at $60{ }^{\circ} \mathrm{C}$ was slowly added to the warm ethanolic solution of zinc acetate. The mixture was stirred for $2 \mathrm{~h}$. The thick white colloidal semi-gel formed was allowed to dry at $80{ }^{\circ} \mathrm{C}$ overnight. The dried xerogel was further calcined at different temperatures $\left(300{ }^{\circ} \mathrm{C}-1000{ }^{\circ} \mathrm{C}\right)$ for $2 \mathrm{~h}$ to get $\mathrm{ZnO}$ powder.

For silver modified $\mathrm{ZnO}$, various mol\% (1, 3, 5 and 10) of silver nitrate dissolved in ethanol were added to the zinc acetate-oxalic acid solution above, with stirring. This was dried as above and calcined at different temperatures for $2 \mathrm{~h}$.

\section{.2.3 Characterisation}

The crystallinity and the effect of silver modification in the crystal phases of the synthesised $\mathrm{ZnO}$ and silver modified $\mathrm{ZnO}$ powders were characterised by X-ray diffraction technique with a Siemens D 500 X-ray diffractometer in the diffraction angle range $2 \theta=20-70^{\circ}$, using $\mathrm{Cu} \mathrm{K}_{\alpha}$ radiation. The crystallite size D of the samples were estimated using the Scherrer's equation, $(0.9 \lambda) /(\beta \cos \theta)$, by measuring the 
line broadening of (101) main intensity peak, where $\lambda$ is the wavelength of $\mathrm{CuK} \alpha$ radiation, $\beta$ is the full width at half maximum and $\theta$ is the Bragg's angle.

Differential Scanning Calorimetry (DSC) measurements were carried out to examine the phase changes using a Rheometric Scientific DSC QC. About $6 \mathrm{mg}$ of the dried sample was heated from room temperature $\left(25^{\circ} \mathrm{C}\right.$ to $500{ }^{\circ} \mathrm{C}$ at a constant heating rate of $10{ }^{\circ} \mathrm{C} / \mathrm{min}$. The formation of $\mathrm{ZnO}$ was confirmed by measuring the FTIR spectra of $\mathrm{ZnO}$ and silver modified $\mathrm{ZnO}$ samples using a GX-FTIR spectrophotometer. In order to study the optical properties, the diffuse reflectance and absorbance spectra of samples were measured using a UV-VIS-NIR Perkin Elmer spectrophotometer. Room temperature photoluminescence spectra of the prepared samples were obtained from Perkin Elmer Luminescence Spectrometer (LS50B). The excitation wavelength was $325 \mathrm{~nm}$, and spectra (uncorrected) were obtained in the range $350 \mathrm{~nm}$ to $600 \mathrm{~nm}$.

\subsection{Photocatalytic studies}

For photocatalytic activity studies, $0.06 \pm 0.005 \mathrm{~g}$ of powdered sample was dispersed in $50 \mathrm{~mL}$ of aqueous rhodamine solution having concentration $5 \times 10^{-6} \mathrm{M}$ at $\mathrm{pH} \sim 6$. The dispersion was irradiated by light using Q-Sun solar simulator $\left(0.68 \mathrm{~W} / \mathrm{cm}^{2}\right.$ at wavelength $\left.340 \mathrm{~nm}\right)$ with stirring. Aliquots were collected at various time intervals to monitor the degradation of rhodamine. Samples were centrifuged and the absorption spectra were measured. The rate constant for degradation was obtained from a first order plot.

\section{Results}

\subsection{Characterisation of Materials}

The powder X-ray diffraction patterns of unmodified and various mol\% of silver modified $\mathrm{ZnO}$ samples calcined at 300 and $400{ }^{\circ} \mathrm{C}$ are shown in Figure 1 . The XRD pattern of $300{ }^{\circ} \mathrm{C}$ calcined samples show peaks corresponding to zinc oxalate dihydrate and the $\mathrm{Ag}$ modified $\mathrm{ZnO}$ samples show peaks corresponding to $\mathrm{Ag}_{2} \mathrm{O}$ in addition to anhydrous zinc oxalate precursors. ${ }^{36}$ Conversely, the spectra of 
$400{ }^{\circ} \mathrm{C}$ samples show typical peak patterns of $\mathrm{ZnO}$ wurtzite structure (JCPDS, 36-1451) and the characteristic peaks of metallic silver. $^{12,31}$
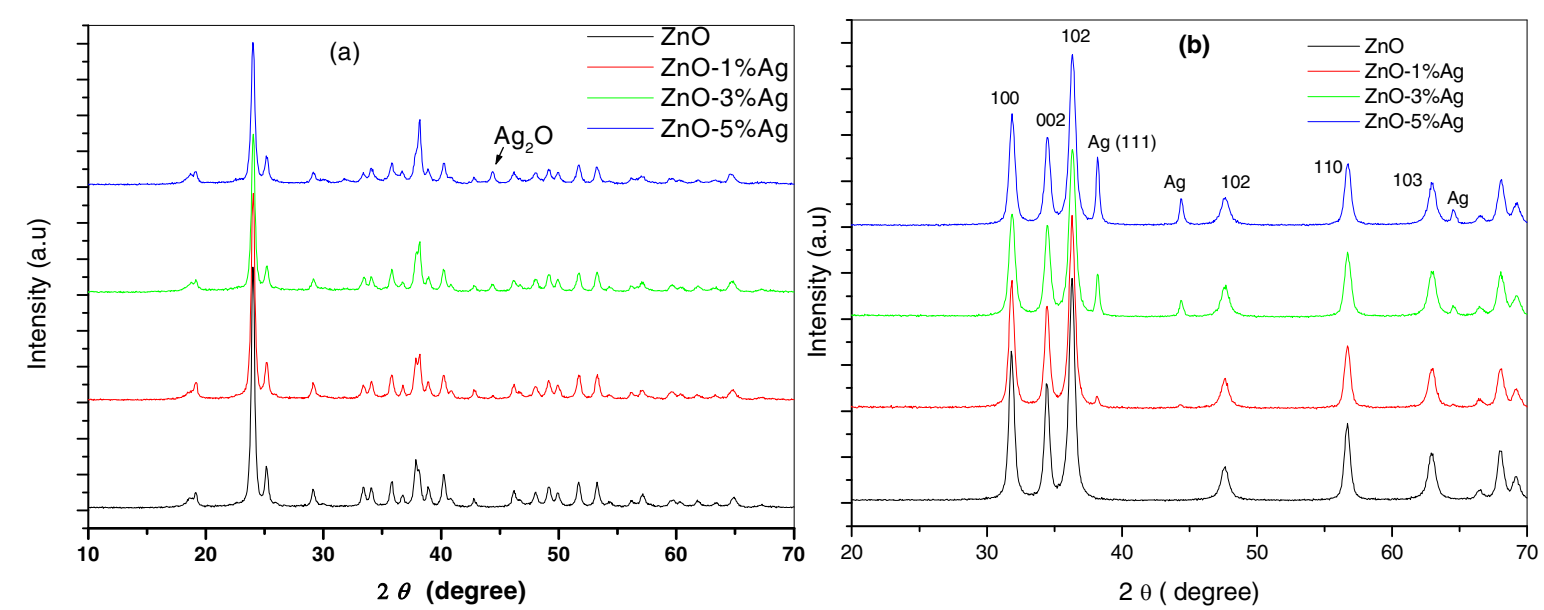

Figure 1: Powder XRD patterns of $\mathrm{ZnO}$ and various mol \% of $\mathrm{Ag}$ modified $\mathrm{ZnO}$ samples calcined at (a) $300{ }^{\circ} \mathrm{C}$ and (b) $400{ }^{\circ} \mathrm{C}$.

Furthermore, a consistent increase in the intensity of silver peaks can be noted with the increase in concentration of $\mathrm{Ag}$ from 1 to $5 \mathrm{~mol} \%$. It should be noted that the formation of metallic silver and the crystalline phase of $\mathrm{ZnO}$ is starting at above $300{ }^{\circ} \mathrm{C}$. This is consistent with the thermal decomposition behaviour of zinc oxalate precursors and $\mathrm{Ag}_{2} \mathrm{O}$ systems. ${ }^{36,37}$ The result also corresponds with a recent observation by Ahn et al who studied the thermal decomposition of $\mathrm{Ag}_{2} \mathrm{O}$ in $\mathrm{ZnO}$ system. ${ }^{38}$ Therefore, we believe that in the present $\mathrm{ZnO}$ system, $\mathrm{Ag}_{2} \mathrm{O}$ is the stable phase at $300{ }^{\circ} \mathrm{C}$ and as the temperature increases to $400{ }^{\circ} \mathrm{C}, \mathrm{Ag}_{2} \mathrm{O}$ decomposes to metallic silver. According to some previous reports, Ag can be incorporated in $\mathrm{ZnO}$ system either as a substituent for $\mathrm{Zn}^{2+}$ or as an interstitial atom. ${ }^{39,40}$ If the silver is substituted for $\mathrm{Zn}^{2+}$, a corresponding peak shift would be expected in the XRD. No such shift in the peak positions was observed in any of our modified samples. This indicates the segregation of Ag particles in the grain boundaries of $\mathrm{ZnO}$ crystallites rather than going into the lattice of $\mathrm{ZnO}$, or only an insignificant quantity may be going to the substitutional $\mathrm{Zn}$ site. 
The crystallite sizes of unmodified $\mathrm{ZnO}$ and various mol\% of $\mathrm{Ag}$ modified $\mathrm{ZnO}$ samples calcined at different temperatures were calculated from the X-ray line broadening using the Scherrer equation. (Supporting Information 1). It is clear that the addition of silver causes a slight reduction in crystallite size. In general, the crystallite size of all the samples increases with increasing calcination temperature (Figure 2), whereas silver facilitates the densification of particles at high temperatures.

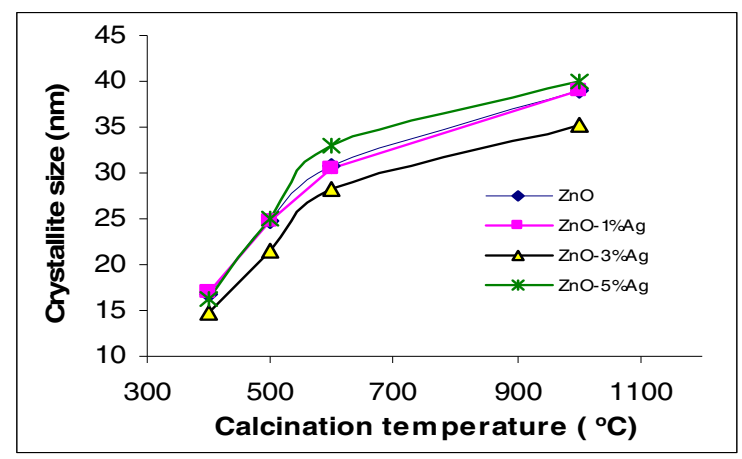

Figure 2: Plot of crystallite size Vs calcination temperature.

In order to understand the thermal events in the samples, DSC has been performed. The DSC curves of $\mathrm{ZnO}$ and $\mathrm{Ag}$ modified $\mathrm{ZnO}(\mathrm{AZ})$ samples are shown in Figure 3. The unmodified $\mathrm{ZnO}$ shows three endothermic peaks starting at 68,104 and $405^{\circ} \mathrm{C}$. On the other hand, 3 mol\% Ag modified $\mathrm{ZnO}$ shows two endothermic peaks at $68,112{ }^{\circ} \mathrm{C}$ and two exothermic peaks at 183 and $395{ }^{\circ} \mathrm{C}$ respectively. The endothermic peak at $\sim 68{ }^{\circ} \mathrm{C}$ corresponds to the elimination of ethanol and the one at $\sim 104{ }^{\circ} \mathrm{C}$ may be attributed to the removal of structural water. The endothermic peak at $405{ }^{\circ} \mathrm{C}$ represents the removal of oxalate species. $^{41}$

In comparison, the exothermic peak observed at $184^{\circ} \mathrm{C}$ for the $\mathrm{Ag}$ modified $\mathrm{ZnO}$ is assumed to be the formation of $\mathrm{Ag}_{2} \mathrm{O}$ where as $\mathrm{Ag}^{+}$is stable in the form of $\mathrm{AgO}_{\mathrm{x}}$ or $\mathrm{Ag}_{2} \mathrm{O}$ at these temperatures. ${ }^{42}$ Interestingly, an intense exothermic peak at $390{ }^{\circ} \mathrm{C}$ shows the thermal decomposition of $\mathrm{Ag}_{2} \mathrm{O}$ to metallic silver, which is in the same temperature region where an endothermic peak is observed for unmodified $\mathrm{ZnO}$; the latter representing the formation of $\mathrm{ZnO}$ at this temperature. This is in good agreement with XRD results and is consistent with a previous report. ${ }^{38}$ The exothermic formation of 
metallic silver is highly energetically favourable than the endothermic evolution of $\mathrm{ZnO}$. In other words, the highly exothermic nature of metal formation predominates in DSC compared to endothermic $\mathrm{ZnO}$ formation. In addition, an increase in silver concentration shows an increase in this peak intensity, which confirms this assumption.

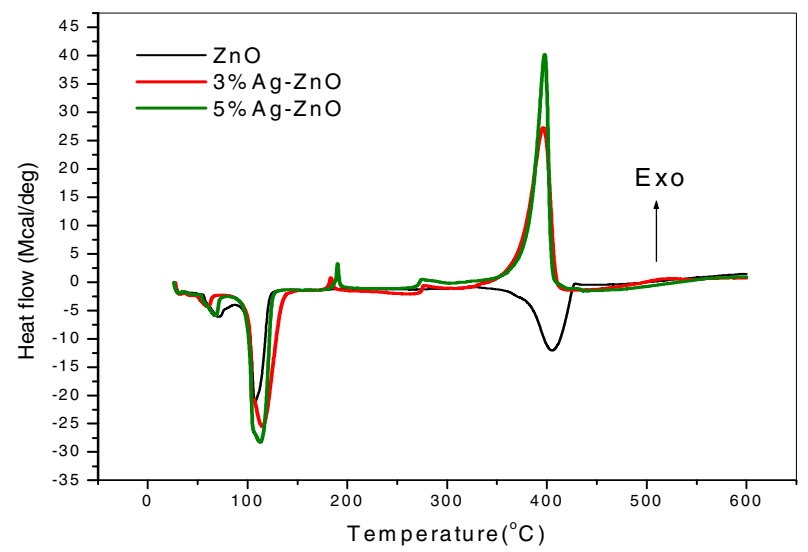

Figure 3: DSC of unmodified $\mathrm{ZnO}$ and $\mathrm{Ag}$ modified $\mathrm{ZnO}$ samples

The formation of nanocrystalline $\mathrm{ZnO}$ wurtzite structure and the effect of silver addition in $\mathrm{ZnO}$ were further confirmed by FT-IR spectral analysis, which is shown in Figure 4. The spectrum of as prepared $\mathrm{ZnO}$ prior to calcination shows an absorption peak at $\sim 3400 \mathrm{~cm}^{-1}$ which corresponds to the O-H stretching of surface adsorbed water molecule. The band at $\sim 2900 \mathrm{~cm}^{-1}$ shows the presence of C-H species. The three bands occurring in the region of $1000-500 \mathrm{~cm}^{-1}$ and the one at $1380 \mathrm{~cm}^{-1}$ correspond to the different modes of $\mathrm{CO}_{3}{ }^{2-}$.

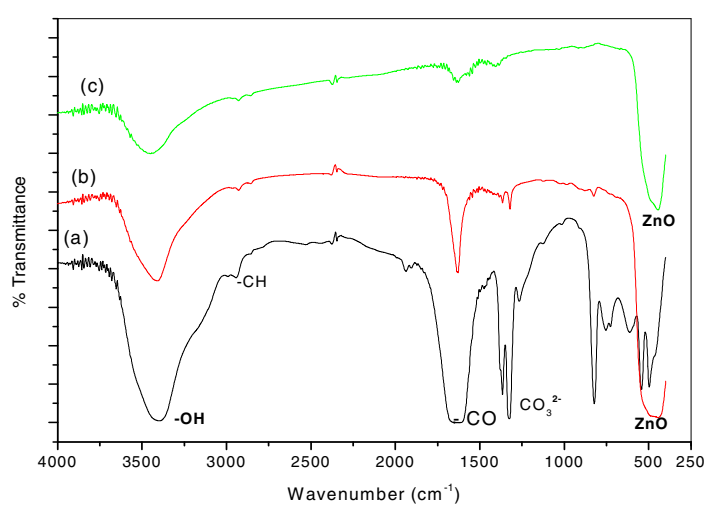

Figure 4: FTIR spectra of $\mathrm{ZnO}$ (a) as prepared at $80{ }^{\circ} \mathrm{C}$, (b) calcined at $400{ }^{\circ} \mathrm{C}$ and (c) $3 \mathrm{~mol} \% \mathrm{Ag}$ modified $\mathrm{ZnO}$ calcined at $400{ }^{\circ} \mathrm{C}$. 
Further the symmetric and asymmetric stretching bands of acetate species can be observed at 1360 and $1600 \mathrm{~cm}^{-1} \cdot{ }^{17}$ All of these indicate that the zinc acetate precursors are present. However, in the case of $\mathrm{ZnO}$ at $400{ }^{\circ} \mathrm{C}$, the peaks corresponding to the organic precursor are no longer present and show the peak of only nanosized $\mathrm{ZnO}$ at $\sim 490 \mathrm{~cm}^{-1}$. The silver modified $\mathrm{ZnO}$ at $400{ }^{\circ} \mathrm{C}$ as well as the IR spectra at $300{ }^{\circ} \mathrm{C}$, however, (Supporting Information 2) show no bands for silver, only that of $\mathrm{ZnO}$, indicating there is no chemical bonding between silver and $\mathrm{ZnO}$.

In order to assess the crystal quality or the amount of defects, Raman analysis has been carried out on the samples. Raman spectra of $\mathrm{ZnO}$ and silver modified $\mathrm{ZnO}$ at $400{ }^{\circ} \mathrm{C}$ are shown in Figure 5. The most intense peak at $436 \mathrm{~cm}^{-1}$ corresponds to $E_{2}$ mode of $\mathrm{ZnO}$ hexagonal wurtzite structure and one at 326 $\mathrm{cm}^{-1}$ should be assigned as the second order Raman spectrum arising from the zone boundary phonons $3 E_{2 \mathrm{H}}-E_{2 \mathrm{~L}}$, while a smaller shoulder at $574 \mathrm{~cm}^{-1}$ is the contribution from $E_{1}(\mathrm{LO})$ mode associated with oxygen deficiency. ${ }^{43}$ A stronger $E_{2}$ mode and much lower $E_{1}$ mode indicate its good crystal quality, with only a very low oxygen vacancy. On the other hand, in addition to the $\mathrm{ZnO}$ peaks the silver modified $\mathrm{ZnO}$ shows a weak peak at $560 \mathrm{~cm}^{-1}$ followed by the peak corresponding to oxygen deficiency.
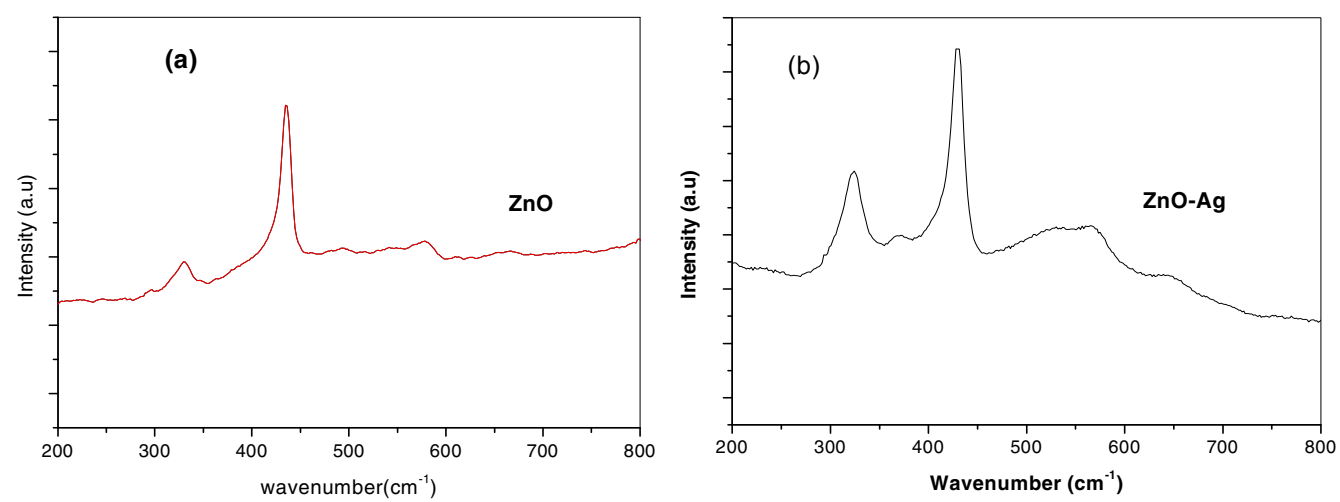

Figure 5: Raman spectra of $\mathrm{ZnO}$ and silver modified $\mathrm{ZnO}$ at $400{ }^{\circ} \mathrm{C}$.

The absorption spectra of unmodified and silver modified $\mathrm{ZnO}$ are presented in Figure 6 and it can be seen that the silver addition does not make any significant reduction in its band gap. 


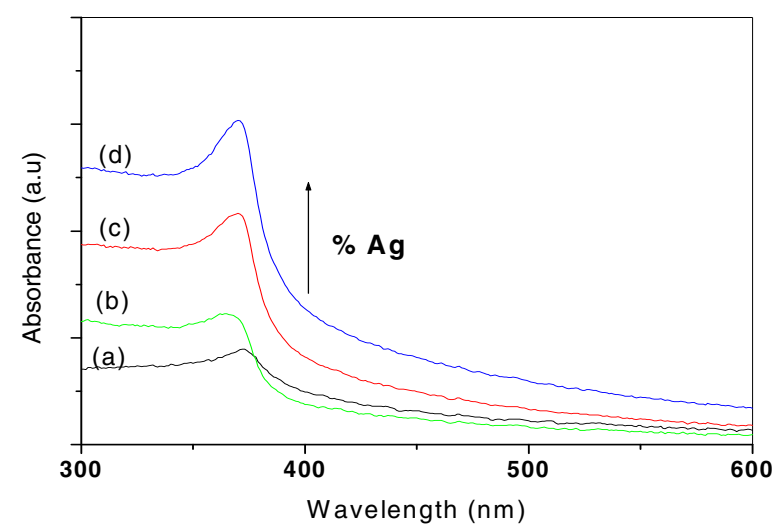

Figure 6: UV-visible absorption spectra of $\mathrm{ZnO}$ (a) and (1-5) mol\% silver modified $\mathrm{ZnO}$ at $400{ }^{\circ} \mathrm{C}$

\subsection{Photocatalytic Activity}

An important aim of the study involves the examination of photocatalytic activity of $\mathrm{ZnO}$ and various mol\% of silver modified $\mathrm{ZnO}$ at different temperatures. The use of an aromatic compound rhodamine 6G (R6G) as a model dye for the photocatalysis study is mainly due to their recurrent occurrence in the industrial field. ${ }^{44,45}$ The photocatalytic activity of unmodified and various mol\% of silver modified $\mathrm{ZnO}$ powders at temperatures ranging from $300-1000{ }^{\circ} \mathrm{C}$ have been studied by analysing the degradation of the dye. The absorption spectra of R6G after undergoing photocatalytic degradation by unmodified and silver modified $\mathrm{ZnO}$ at $400{ }^{\circ} \mathrm{C}$ are shown in Figure 7 . The degradation is monitored by studying the decrease in absorbance of R6G in presence of powdered sample suspensions, and quantified by plotting a first order decay plot of the absorbance at $525 \mathrm{~nm}$.

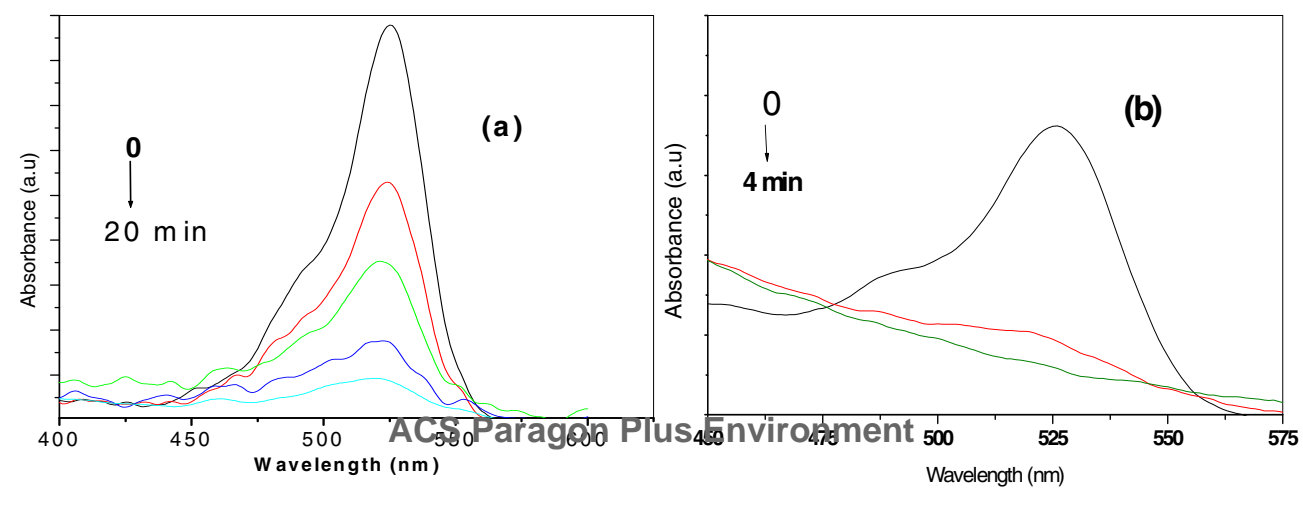


Figure 7: UV-visible absorption spectra of degradation of $\mathrm{R} 6 \mathrm{G}$ by (a) $\mathrm{ZnO}$ and (b) 3 mol\% silver modified $\mathrm{ZnO}$ at $400{ }^{\circ} \mathrm{C}$

In the case of metal modification in nanoparticles, a particular concentration of metal modifier can tune the photophysical properties. From the study, it can be seen that the addition of silver enhances the photocatalytic degradation of the dye up to $3 \mathrm{~mol} \%$ and above this concentration it shows a decrease in the rate of activity. The higher percentage of silver could be unfavourable to photocatalytic efficiency. It is assumed that amount of silver below its optimum, can act as electron-hole separation centres. ${ }^{46}$ When the Ag loading above its optimum, it can also act as charge carrier recombination centres. This is because the possibility of hole capture increases by large number of negatively charged Ag particle on $\mathrm{ZnO}$ which reduces the efficiency of charge separation when the silver content is above its optimum. ${ }^{47}$

Hence, in the present system, the optimum amount of silver giving the highest photocatalytic activity (Figure 8) is determined to be $3 \mathrm{~mol} \%$ whose rate of degradation is four times greater $\left(0.42 \mathrm{~min}^{-1}\right.$, degrade the dye within $4 \mathrm{~min})$ compared to the rate with pure $\mathrm{ZnO}\left(0.10 \mathrm{~min}^{-1}\right.$, degrade the dye within $20 \mathrm{~min}$ ). The samples at $400{ }^{\circ} \mathrm{C}$ show a better photocatalytic activity than the samples at higher temperatures, which may be attributed to the smaller crystallite size and a reasonably good surface area. (Supporting Information 1). The surface area analysis of $\mathrm{ZnO}\left(32 \mathrm{~m}^{2} / \mathrm{g}\right)$ and $3 \%$ silver modified $\mathrm{ZnO}($ $173 \mathrm{~m}^{2} / \mathrm{g}$ ) at this temperature shows good agreement with this activity. It should be noted that the Ag modified samples (3 and $5 \mathrm{~mol} \%$ ) showed almost similar rate of photocatalytic activity at higher temperatures such as $400-600{ }^{\circ} \mathrm{C}$ and hence $3 \mathrm{~mol} \%$ silver is found to be as the optimum concentration. 


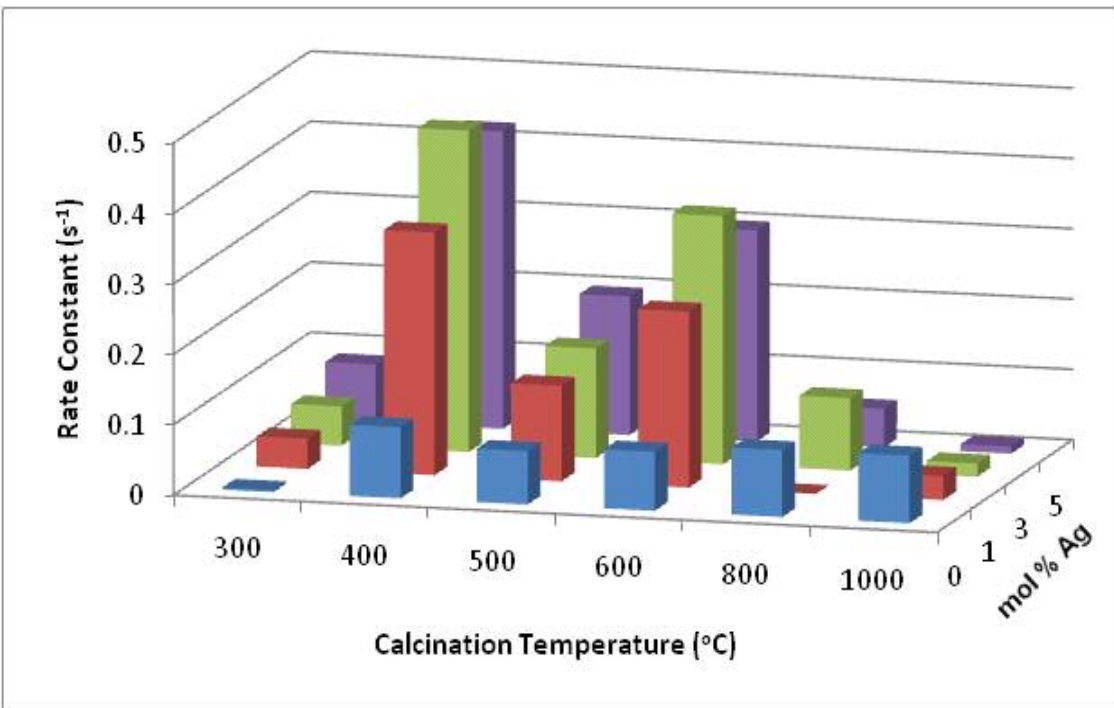

Figure 8: Plot of concentration of silver vs. rate constants of degradation reaction obtained from kinetic analysis.

Nevertheless, at higher temperatures, it is found that there is no positive effect of silver addition in the photocatalytic activity $\left(800-1000{ }^{\circ} \mathrm{C}\right)$ (Supporting Information 3$)$. On the other hand, the silver modification is photocatalytically effective only at low temperatures. This is because the presence of silver promotes the densification and grain growth of $\mathrm{ZnO}$ at high temperatures ${ }^{48}$ by forming silver island in the $\mathrm{ZnO}$ matrix, which causes the reduction in active surface sites of the photocatalyst for the adsorption of degradants and for the absorption of light. This conclusion has been further confirmed by BET analysis of high temperature $\left(800{ }^{\circ} \mathrm{C}\right)$ calcined sample which shows a lower surface area and pore volume for silver modified $\mathrm{ZnO}\left(2.65 \mathrm{~m}^{2} / \mathrm{g}, 0.005 \mathrm{cc} / \mathrm{g}\right)$ than the pure $\mathrm{ZnO}\left(4.34 \mathrm{~m}^{2} / \mathrm{g}, 0.012 \mathrm{cc} / \mathrm{g}\right)$. The crystallite size of 3 mol\% Ag modified sample showed the smallest size values among the samples and had good photocatalytic activity. 3 mol\% may therefore be assumed as the optimum concentration of $\mathrm{Ag}$ particles for the present $\mathrm{ZnO}$ system. This is similar to previous findings for silver loading in titania materials $^{31}$ and to other work involving cobalt on conbalt oxide/titania systems. ${ }^{49}$

Although there is no formation of $\mathrm{ZnO}$ at $300{ }^{\circ} \mathrm{C}$, the silver modification causes the zinc oxalate precursor at $300{ }^{\circ} \mathrm{C}$ to show improved photocatalytic activity. This may be due to the fact that $\mathrm{Ag}_{2} \mathrm{O}$ is 
present in the system, which is also a metal oxide, and can produce holes on light illumination resulting in hydroxyl radicals which subsequently degrade the dye. ${ }^{50}$

The visible light activity of these materials has also been analysed in presence of Dublin sunlight and it is found that silver modified $\mathrm{ZnO}$ shows 5 times higher rate of degradation of the dye than the pure $\mathrm{ZnO}$ (Supporting Information 4) which is an indication that these silver modified materials could be utilised for sunlight driven photocatalytic processes.

\subsection{Photoluminescence Studies}

Photoluminescence (PL) studies give an insight into the optical and photochemical properties of $\mathrm{ZnO}$. Information on the quality of crystals, structural defects (surface oxygen vacancies, $\mathrm{Zn}$ interstitials etc) and particle surfaces can be garnered from PL spectra. The room temperature PL emission spectra (excitation at $325 \mathrm{~nm}$ ) of $\mathrm{ZnO}$ and various mole $\%$ of $\mathrm{Ag}$ modified $\mathrm{ZnO}$ samples calcined at $400{ }^{\circ} \mathrm{C}$ are shown in Figure 9. All samples emit strongly in the UV with a band centred at $390 \mathrm{~nm}$, corresponding to the excitonic emission and three other less intense peaks. The weak blue band at $421 \mathrm{~nm}$ and $480 \mathrm{~nm}$ correspond to band edge free excitons and bound excitons respectively. ${ }^{51}$ Furthermore, there is a weak green emission at $530 \mathrm{~nm}$. The exact reason for this green emission is still controversial. A number of hypotheses have been proposed to explain this such as transition between electron close to the conduction band and a deeply trapped hole at $\mathrm{V}_{\mathrm{o}}^{++}$, surface defects like $\mathrm{Zn}^{2+}$ vacancies, due to the transition between anti-site oxygen and donor-acceptor complexes, ${ }^{52}$ etc. Surface binding of carboxylate ions is also known to improve the emission yield as they create vacancies that can facilitate the visible emission. $^{53}$ 


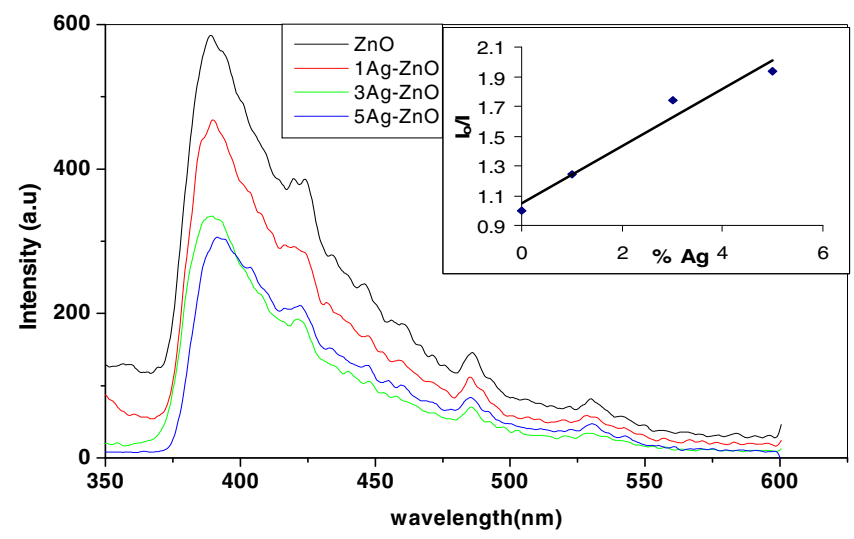

Figure 9: Room temperature PL spectra of $\mathrm{ZnO}$ and various mole \% of $\mathrm{Ag}$ modified $\mathrm{ZnO}$ samples calcined at $400{ }^{\circ} \mathrm{C}$. (Excitation at $325 \mathrm{~nm}$ ). Inset shows the relative intensity change of emission in presence of silver. Emission intensities were measured at $390 \mathrm{~nm}$.

According to some reports, this longer wavelength emission is due to the recombination of photogenerated hole with the singly ionized oxygen vacancy site. ${ }^{54,55}$ Our study agrees with this report as the presence of oxygen vacancies is also confirmed from the Raman analysis. The weak green emission and strong exciton emission of the materials demonstrate its good crystal quality.

Also it could be seen from the PL spectra that, the UV emission is decreasing with an increase in silver content indicating the decreased electron-hole recombination. This decrease in emission intensity is in accordance with the Stern- Volmer quenching and similar results were previously reported. ${ }^{56}$

\section{Discussion}

\subsection{Effect of Synthetic Parameters on Photocatalytic Activity}

A non-aqueous sol-gel process adopted for the present study helps Ag particles to disperse well in the $\mathrm{ZnO}$ matrix. Such a distribution is observed to be favouring the tuning of structural features for achieving better photocatalytic activity, which was found to be better (three times) than the commercial photocatalyst, Degussa P25. The silver modified samples at $400{ }^{\circ} \mathrm{C}$ are found to be highly photoactive, with nanocrystalline $\mathrm{ZnO}$ formed at this temperature. The formation of nanocrystalline $\mathrm{ZnO}$ at $400{ }^{\circ} \mathrm{C}$ was also reported by Wang et $a l^{57}$ where crystalline $\mathrm{ZnO}$ nanowires in presence of gold were observed. The segregation of metallic Ag particles around the highly crystalline $\mathrm{ZnO}$ grain boundaries may be the 
reason for the high photocatalytic activity of the $400{ }^{\circ} \mathrm{C}$ calcined samples. The incorporation of silver can be represented according to Scheme (1).

$\mathrm{ZnO}_{\text {(precur) }}+2 \mathrm{Ag}^{+}+\mathrm{O}_{2} \rightarrow \mathrm{ZnO}_{\text {(precur) }}+\mathrm{Ag}_{2} \mathrm{O}+1 / 2 \mathrm{O}_{2}, \quad \mathrm{~T}<350$

Like monovalent dopant such as $\mathrm{K}^{+}, \mathrm{Na}^{+}$, silver can perform as amphoteric dopant according to scheme (2), where $\operatorname{Ag}_{(Z n)}$ is the silver occupied in the $\mathrm{Zn}$ site and $\mathrm{Ag}_{(i)}$ is the $\mathrm{Ag}$ in the interstitial site.

$\mathrm{ZnO}+\mathrm{Ag}_{2} \mathrm{O} \rightarrow \mathrm{Ag}_{(\mathrm{Zn})}+\mathrm{Ag}_{(i)}+\mathrm{ZnO}+1 / 2 \mathrm{O}_{2}, \quad \mathrm{~T}>350$

In the present case, the presence of $\mathrm{Ag}$ in the $\mathrm{ZnO}$ lattice is ruled out given the absence of a shift in the X-ray peak position. Because of the difference in ionic radii between $\mathrm{Ag}^{+}(1.22 \AA)$ and $\mathrm{Zn}^{2+}(0.72 \AA)$, the silver particles preferentially choose to segregate around the $\mathrm{ZnO}$ grain boundaries. It is also observed from XRD that metallic Ag particles are formed only at $400{ }^{\circ} \mathrm{C}$. Indeed, the $300{ }^{\circ} \mathrm{C}$ samples show the X-ray reflections corresponding to zinc acetate precursor and $\operatorname{Ag}_{2} \mathrm{O}$. This observation corroborates with previous reports, where the thermal decomposition behaviour of $\mathrm{ZnO}$ precursors was studied. $^{12}$ Also it has been reported that the thermal decomposition of $\mathrm{AgO}_{\mathrm{x}}$ into $\mathrm{Ag}$ occurs in the temperature range $350-400{ }^{\circ} \mathrm{C} .{ }^{58,59}$ Our observations are similar to this study and to the other reports which describe the thermal stability of chemically precipitated $\mathrm{Ag}_{2} \mathrm{O}$ powders. ${ }^{60,61}$

Ahn et al have also studied the thermal decomposition of $\mathrm{Ag}_{2} \mathrm{O}$ in $\mathrm{ZnO}$ system, where they reported that the thermal decomposition of $\mathrm{Ag}_{2} \mathrm{O}$ to metallic silver occurs above $380{ }^{\circ} \mathrm{C}{ }^{38}$ These findings are in good agreement with the DSC result, where the crystallization of $\mathrm{ZnO}$ as well as the decomposition of $\mathrm{Ag}_{2} \mathrm{O}$ occurs above $380^{\circ} \mathrm{C}$. It is also evident from XRD that the incorporation of $\mathrm{Ag}$ into the $\mathrm{ZnO}$ matrix does not make considerable change in the crystalline growth of nano $\mathrm{ZnO}$ compared to unmodified $\mathrm{ZnO}$. However, the incorporation of $3 \mathrm{~mol} \% \mathrm{Ag}$ at $400{ }^{\circ} \mathrm{C}$ was found to be inhibiting the temperature dependent crystal growth of $\mathrm{ZnO}$. Therefore, $3 \mathrm{~mol} \%$ can be assumed as the optimum concentration of Ag particles required for the effective homogeneous distribution in the $\mathrm{ZnO}$ matrix by which the 
properties can be tuned effectively. On increasing concentration, the Ag particles can aggregate together and form localized clusters, which reduce the possibility of a homogeneous distribution and thereby reduce the surface availability for the adsorption of reactant and light.

Moreover, at high temperatures, since the Ag-O bond strength is weaker than the Ag-Ag bond strength, the formed $\mathrm{Ag}^{\mathrm{o}}$ has higher surface energy eventually will form metallic clusters, which facilitate the densification of $\mathrm{ZnO}$ which reduces the surface area and hence the photocatalytic activity. The photocatalytic activity is dependent on the exposed surface area of the photocatalyst as it provides a means for the surface adsorption of the degradant. These results appear consistent with studies of Dodd et $a l^{62}$ who reported that there exists an optimum particle size for maximum photocatalytic activity of $\mathrm{ZnO}$. This optimum particle size of $\sim 15 \mathrm{~nm}$, in the present study, was achieved by the suitable amount of silver addition. It is evident from the crystallite size (Figure 2) that 3 mol\% silver modified $\mathrm{ZnO}$ at $400{ }^{\circ} \mathrm{C}$ shows a smaller crystalline size among other samples. The distribution of silver in the $\mathrm{ZnO}$ matrix resulted in a reduction in the crystallite size. In a particular system, a smaller particle size, which causes the specific surface area to increase, is expected to enhance the surface active sites where the photogenerated charge carriers are able to react with surface adsorbed molecule to form active radicals. High crystallinity with a low particle size results in a reasonable surface area for enhanced photocatalytic activity.

As well as surface modification, it is evident from the absorption spectra that the silver addition can enhance the absorption capability of $\mathrm{ZnO}$. Even though there is no considerable change in the band gap (calculated from diffuse reflectance spectra), the energy levels of silver lying in between the VB and CB of $\mathrm{ZnO}$ may facilitate the enhanced light absorption capability. 


\subsection{Mechanism of Enhancement of Photocatalytic Activity by Silver}

One of the major aims behind the modification of semiconductors with noble metals is to improve or tune the catalytic and sensing properties. The deposition of noble metals on semiconductor nanoparticles is an effective way for improving the photocatalytic efficiency as the metal modifier can indirectly influence the interfacial charge transfer processes. As a noble metal, silver can act as electron scavenger and store them effectively. Certainly, a primary understanding of photoinduced interactions as well as the interfacial charge transfer processes in metal modified semiconductors is important to explain the exact role of metal in semiconductor photocatalysis. Light absorption of a suitable wavelength by $\mathrm{ZnO}$ results in the promotion of an electron from the valence band to the conduction band. The resulting hole is primarily responsible for the formation of hydroxyl radicals, which subsequently degrade the pollutants adsorbed onto the surface of the photocatalyst. ${ }^{63}$ In such a photocatalytic process, the separation and recombination of photoinduced charge carriers are competitive pathways and photocatalytic activity is effective when recombination between them is prevented. The extent of recombination can be gauged by the intensity of luminescence.

In the present case, the UV emission at $390 \mathrm{~nm}$ of $\mathrm{ZnO}$ reduces as a function of mol \% of silver (Figure 9). This gradual decrease can be ascribed to the electron trapping effect of Ag, which acts as an acceptor species, hindering the recombination of charge carriers on $\mathrm{ZnO}^{64}$ Similar results were found with titanium dioxide. $^{65}$ The Fermi level of silver, which lies below the conduction band of $\mathrm{ZnO}$, energetically favours the transfer of electrons from $\mathrm{ZnO}$. In order to assess the nature of photocatalytic degradation of $\mathrm{R} 6 \mathrm{G}$, we analysed the emission spectra of $\mathrm{ZnO}$ and silver modified $\mathrm{ZnO}$ in presence of R6G which is shown in Figure 10. 


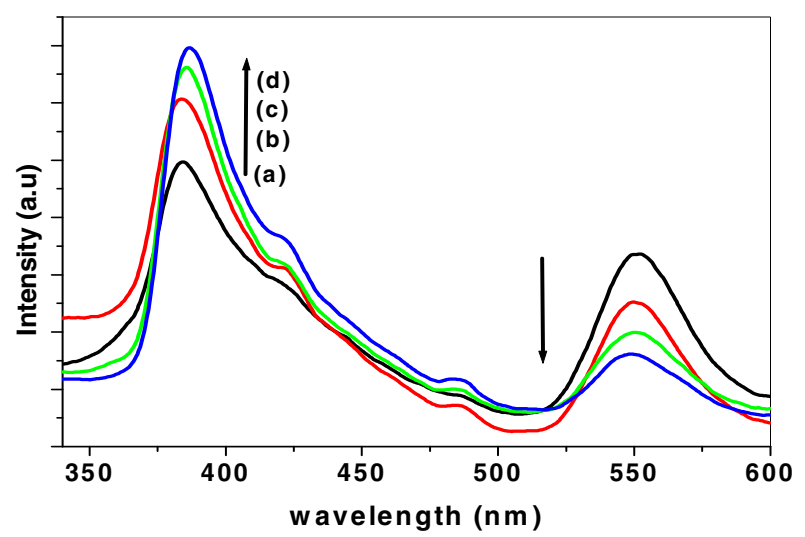

Figure 10: Room temperature PL spectra of (a) $\mathrm{ZnO}$ and (b), (c), (d) are 1, 3 \& 5 mol\% Ag modified $\mathrm{ZnO}$ respectively in presence of $\mathrm{R} 6 \mathrm{G}$. Emission at 390nm corresponds to $\mathrm{ZnO}$ emission and at $\sim 550 \mathrm{~nm}$ corresponds to R6G.

An increase in intensity of UV emission $(390 \mathrm{~nm})$ of $\mathrm{ZnO}$, as a function of amount in silver was observed, which is reverse in the case of samples without R6G. Interestingly, this increase in $\mathrm{ZnO}$ emission coincides with the decrease in emission of $\mathrm{R} 6 \mathrm{G}$ at $\sim 550 \mathrm{~nm}$ indicating that there is an additional photoelectrochemical process that dominates the electron capturing by silver at the time of photodegradation of R6G. These findings indicate the degradation of R6G on the silver modified $\mathrm{ZnO}$ surfaces may occur by a simultaneous two stage charge transfer processes.

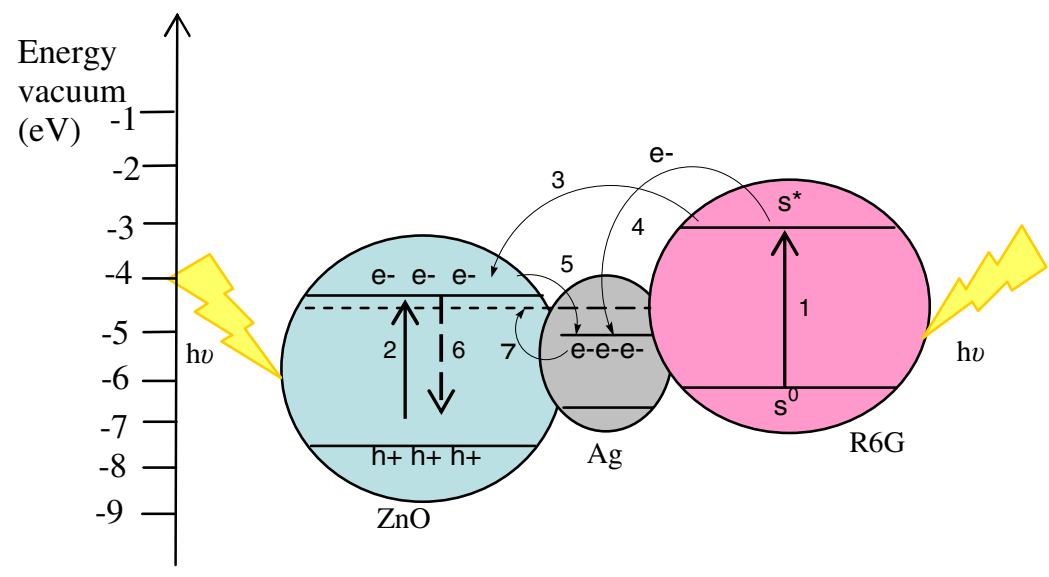

Figure. 11: Schematic showing the electron transfer events of Ag-ZnO system in presence of R6G. (1) $\mathrm{S}^{0}$ to $\mathrm{S}^{*}$; (2) VB to $\mathrm{CB}$ in $\mathrm{ZnO}$ (charge carrier generation; (3) $\mathrm{S}^{*}$ to $\mathrm{CB}$ of $\mathrm{ZnO}$; (4) $\mathrm{S}^{*}$ to $\mathrm{Ag}$; (5) $\mathrm{CB}$ of $\mathrm{ZnO}$ to $\mathrm{Ag}$ and (6) $\mathrm{CB}$ to $\mathrm{VB}$ of $\mathrm{ZnO}$ (charge carrier recombination (7) Shifting of Fermi level of silver. 
The high reduction potential of $\mathrm{S}^{*}, \mathrm{CB}$ of $\mathrm{ZnO}(-0.8 \mathrm{~V} \mathrm{Vs} \mathrm{NHE})$ and of $\mathrm{Ag}(0.15 \mathrm{~V})$ (according to literature data $)^{66,67}$ drives its electron injection reactions.

The possible interfacial charge transfer events in the silver modified semiconductor at the time of degradation of dye can be explained by using the diagram presented in Figure 11. After the initial events such as the (1) ground state singlet to singlet excitation in dye and (2) band-gap excitation in $\mathrm{ZnO}$, the possible electron transfer processes that can happen in the $\mathrm{Ag}-\mathrm{ZnO}$ system in photocatalytic degradation of R6G are transfer of elctrons from (3) sensitized dye to the conduction band of $\mathrm{ZnO}$, (4) sensitized dye to $\mathrm{Ag}$ particles, (5) from the $\mathrm{CB}$ of $\mathrm{ZnO}$ to $\mathrm{Ag}$, (6) from the $\mathrm{CB}$ of $\mathrm{ZnO}$ to its $\mathrm{VB}$ (recombination) and sensitized dye to the shallow trap levels in the band gap of ZnO. From the UV-vis and PL spectra it is found that an increase of Ag concentration in the system enhances the UV emission of $\mathrm{ZnO}$ in presence of $\mathrm{R} 6 \mathrm{G}$, while diminishes in the absence of dye. This could be ascribed to the extent of hole formation as a function of Ag concentration. ${ }^{68}$ The greater the formation of holes, the more intense the UV emission, provided all charge carriers are recombining effectively. However, in the absence of $\mathrm{R} 6 \mathrm{G}$, the $\mathrm{CB}$ electrons of $\mathrm{ZnO}$ generated as a result of the band-gap excitation are captured by the Ag particles and the recombination is reduced significantly; hence we observe a decrease in emission intensity as the Ag concentration increases. Further, an increase in the hole concentration formed as a function of Ag addition also found to enhace the UV emission by a similar mechanism. In presence of $\mathrm{R} 6 \mathrm{G}$, however, the $\mathrm{CB}$ electron population in $\mathrm{ZnO}$ is retained by the electron injection from the dye, which also simultaneously populates the electron level in Ag. Both processes (4) and (5) are possible in the case of silver because of the position of its energy level. ${ }^{69}$ This electron transfer will continue until the overall Fermi level of the metal modified $\mathrm{ZnO}$ system shifts towards more negative potential (7) and ultimately equillibrates with that of $\mathrm{ZnO} .{ }^{70}$ Once this level is reached, Ag discharges the stored electrons in to the solution where they react with dissolved oxygen to form the superoxides and $\mathrm{OH}$ radicals in turn. These active oxygen species react with the dye molecules and degrade them effectively. 
If there was back electron transfer between the excited dye cation radical $\left(\right.$ dye $\left.\mathrm{e}^{+\bullet}\right)$ and $\mathrm{ZnO}\left(\mathrm{e}^{-}\right)$, the dye would have regenerated. However, no dye regeneration was observed which indicates suppression of this back electron transfer by silver. Hence, there is a role for silver in utilising the captured electrons and thereby the free holes in the case of a system containing sensitizing dye. The enhanced photocatalytic activity of semiconductors modified with Ag are previously reported to be due to the generation of more free VB holes as a function of silver addition. However, in the present case, active oxygen species such as $\mathrm{OH}$ radicals and $\mathrm{O}_{2}{ }^{-}$generated by the $\mathrm{CB}$ electrons are found to be major species responsible for the dye degradation. Both the sensitizing property of dye and electron scavenging ability of silver together constitute to the interfacial charge transfer process in such a way to utilise the photoexcited electrons, in addition to the VB holes, to form this active oxygen species. The high reduction potential of the dye used is found to be the key factor that governs the electron transfer process and thereby defines the mechanism of photocatalytic degradation.

\section{Conclusions}

Various mol\% of highly active silver modified and unmodified $\mathrm{ZnO}$ photocatalysts at different temperatures were prepared through a non aqueous sol gel route. The structural and optical properties of the resultant materials were characterised by XRD, DSC, FT-IR, Raman, UV-Vis, and PL spectroscopy. The materials synthesised $\left(\mathrm{T}>400{ }^{\circ} \mathrm{C}\right)$ were shown to have a high crystal quality. The silver modification was effective at low temperatures such as $400-600{ }^{\circ} \mathrm{C}$ and results in a reduction of the crystallte size of the $3 \%-\mathrm{Ag}$ material relative to $\mathrm{ZnO}$. Photocatalytic activity of all samples were determined by analysing the degradation of rhodamine $6 \mathrm{G}$ in presence of the powdered suspensions. Silver modification caused the material to show significant improvement in the photocatalytic activity. 3 mol\% silver at $400{ }^{\circ} \mathrm{C}$ was considered as the optimum concentration which shows four times higher rate of degradation of dye than that of unmodified $\mathrm{ZnO}$. The mechanism of photocatalytic activity was studied by analysing the emission properties and it was found that the presence of silver facilitates the interfacial charge transfer processes in such a way to utilise the $\mathrm{CB}$ electron for enhancing the 
photocatalytic activity. This results show that silver has a significant role to play in the trapping of electrons in these materials, and as such these materials applications could be extend to the development of a photocatalyst which is applicable in both environmental purification and energy production processes.

\section{Acknowledgements}

RG acknowledges HEA Strand I for funding

Supporting Information available: Table of crystallite sizes for all samples, IR spectra of silver modified $\mathrm{ZnO}$ samples at $300{ }^{\circ} \mathrm{C}$ and Table of rate constants of photodegradation of $\mathrm{R} 6 \mathrm{G}$ and sunlight photocatalysis kinetic data. This material is available free of charge via the Internet at http://pubs.acs.org.

\section{References}

1 Afzaal, M.; Malik, M. A.; O'Brien, P. New J. Chem. 2007, 31, 2029

2 Kamat, P.V. J. Phys. Chem. C 2007, 111, 2834. 2029.

3 Mills, A.; Wang, J. J. Photochem. Photobiol. A: Chem. 2006,182, 181

4 Hoffmann, M. R.; Martin, S. T.; Choi, W.; Bahnemann, D. W. Chem. Rev. 1995, 95,69

5 Vayssieres, L. Adv. Mater. 2003, 15, 464.

6 Periyat, P.; Pillai, S. C.; McCormack, D. E; Colreavy, J., Hinder, S. J. J. Phys. Chem. C 2008, 112, 44.

7 Pang, Z.W.; Dai, Z. R; Wang, Z. L. Science 2001, 291, 1947.

8 Bahadur, L.; Rao, T. N. J. Photochem. Photobiol. A: Chem. 1995, 91, 233.

9 Norris, B. J.; Anderson, J.; Wager, J. F.; Keszler, D. A. J. Phys. D. Appl. Phys. 2003, 36, 105.

10 Lee, J. B.; Lee, H. J.; Seo, S. H.; Park, J. S. Thin Solid Films 2001, 641, 398.

11 Hu, Z.; Chen, S.; Peng, S. J. Coll. Interface Sci., 1996, 182,457.

12 Pillai, S. C.; Kelly, J. M.; McCormack, D.E.; Raghavendra, R. J. Mater. Chem. 2004, 14, 1572. 
13 Pillai, S. C.; Kelly, J. M.; McCormack, D. E.; O’Brien, P.; Raghavendra, R. J. Mater. Chem. 2003, $13,2586$.

14 Gouvea, C. A. K.; Wypych, F.; Moraes, S. G.; Duran, N.; Peralta-Zamora, P. Chemosphere 2000, 40, 427.

15 Sang, B.; Konagai, M. J. Appl. Phys. 1996, 35, 602.

16 Dionysiou, D. D.; Suidan, M. T.; Bekou, E.; Baudin, I.; Laîné, M. J. Appl. Catal. B: Environ. 2000 $26,153$.

17 Sibu, C. P.; Kumar, S. R.; Mukundan, P.; Warrier, K. G. K. Chem. Mater. 2002, 14, 2876.

18 Padmanabhan, S. C.; Pillai, S. C.; Colreavy, J.; Balakrishnan, S.; McCormack, D. E.; Perova, T. S.; Gun'ko ,Y.; Hinder, S. J.; Kelly, J. M. Chem. Mater. 2007, 19 , 4474.

19 Subramanian, V.; Wolf, E.; Kamat, P. V. J. Phys. Chem. B 2001,105, 11439.

20 Pillai, S. C.; Periyat, P.; George, R.; McCormack, D. E.; Seery, M. K.; Hayden, H.; Colreavy, J.; Corr, D.; Hinder S. J. J . Phys. Chem. C 2007, 111, 1605.

21 Asahi. R.; Morikawa, T.; Ohwaki, T.; Aoki, K.; Taga, Y. Science 2001, 13, 269.

22 Qui, X.; Li, G.; Sun, X.; Li, L.; Fu, X. Nanotech. 2008, 19, 215703.

23 Hariharan, C.; Appl. Cat. A: Gen. 2006, 304, 55.

24 Kamat, P. V.; Huehn, R.; Nicolaescu, R.; J. Phys. Chem. B 2002, 106, 788.

25 Hermann, J. M.; Tahiri, H.; Ait-Ichou, Y.; Lossaletta, G.; Gonzalez-Elipe, A. R.; Fernandez, A. Appl. Catal. B: Environ. 1997,13, 219.

26 Kamat, P. V. J. Phys. Chem. B 2002, 106, 7729.

27 Kang, H. S.; Ahn, B. D.; Kim, J. H.; Kim, G. H.; Lim, S. H.; Chang, H. W.; Lee, S. Y. Appl. Phys. Lett. 2006, 88, 202108.

28 Pathak, P.; Meziani, M. J.; Castillo, L.; Sun, Y. P. Green Chem. 2005, 7, 667.

29 Chao, H. E.; Yun, Y. U.; Xiangfang, H. U.; Larbot, A. J. Eur. Cer. Soc. 2003, 23,1457.

30 Stathatos, E.; Petrova, T.; Lianos, P. Langmuir 2001,17 ,5025.

31 Seery, M. K; George, R.; Floris, P.; Pillai, S .C. J. Photchem. Photobio. A: Chem. 2007,189 (2-3), 258.

32 Hirakawa, T.; Kamat, P. V. J. Am. Chem. Soc. 2005, 127, 3928.

33 Wang, R.; Xina, J. H.; Yang, Y.; Liu, H.; Xu, L.; Hu, J. Appl. Surf. Sci. 2004, 227, 312.

34 Jeong, S.H.; Park, B.N.; Lee, S. B.; Boo. J. H. Surf. Coat. Tech. 2005, 193, 340.

35 Height, M. J.; Pratsinis, S. E.; Mekasuwandumrong, O.; Praserthdam, P. Appl. Cat. B: Environ. 2006, 63, 305.

36 Pillai, S. C.; Kelly, J. M.; McCormack, D.E.; Ramesh, R. Mater. Sci. Tech. 2004, $20,964$. 
37 Spanhel, L.; Anderson, M.A. J. Am. Chem. Soc. 1991, 113, 2826.

38 Ahn, B. D.; Kang, H. S.; Kim, J. H.; Chang, H. W.; Lee, S.Y. J. Appl. Phys. 2006, 100, 093701.

39 Fan, J.; Freer, R. J. Appl. Phys. 1995,77, 9.

40 Blinks, D. J.; Grimes, R. W. J. Am. Ceram. Soc. 1993, 76, 2370.

41. Pillai, S. C.; Kelly, J. M.; McCormack, D.E.; Ramesh, R. J. Mater. Chem. 2008, DOI:10.1039/b804793f.

42 Chuang H. J.; Ko, H. W. Proc. Natl. Sci. Counc., Repub. China A: Phys. Sci. Eng. 1989, 13, 145

43 Wu, J. J.; Liu, S. C. J. Phys. Chem. B 2002, 106, 9546.

44 Aarthi, T.; Madras,G. Ind. Eng. Chem. Res. 2007, 46, 7.

45 Qiu Y.; Zhang, F; Zhao, F; Tang Y.; Song X. J. Photochem. Photobiol. 1995, 85(3), 281.

46 Hermann, J. M.; Disdier, J.; Pichat, P. J. Phys. Chem. 1986, 90, 6028.

47 Sclafani, A.; Hermann, J. M. J. Photochem. Photobiol. A 1998, 113, 181.

48 Kuo, S.T.; Tuan ,W.H.; Shieha, J.; Wang, S.F. J. Eur. Ceram. Soc. 2007, 27, 4521.

49 Yang, Q.J.; Choi, H.; Dionsyiou, D. D. Appl. Cat. B: Environ. 2007, 74, 170.

50 Zhang, L.; Yu.; J. C.; Yip H. Y.; Li, Q.; Kwong, K.W.; Xu, A.W.; Wong, P.K. Langmuir 2003, 19, 10372 .

51 Vanheusden, K.; Warren, W. L.; Seager, C. H.; Tallant, D. R.; Voigt, J. A. J. Appl. Phys. 1996, 79, 7983.

52 Djurisic, A.B.; Leung, Y.H.; Choy, C. W. C. H.; Cheah, K.W.; Chan.W.K. Appl. Phys. Lett. 2004, 84, 2635.

53 Kamat; P. V.; Patrick, B. J. Phys. Chem. 1992, 96, 6829.

54 Manticone, S.; Tefeu, R.; Kanaev,A.V. J. Phys. Chem. B 1998,102, 2854.

55 Yao, B.D.; Chan, Y.F.; Wang, N. Appl. Phys. Lett. 2002, 81, 757.

56 Subramanian, V.; Wolf, E. E.; Kamat, P.V. J. Phys. Chem. B 2003, 107, 7479.

57 Wang, X.; Li, Q.; Liu, Z.; Zhang, J.; Liu, Z. Appl. Phys. Lett. 2004, 84, 4941.

58 Kanai, Y. J. Appl. Phys. 1991, 30, 2021.

59 Waterhouse, G. I. N.; Bowmaker, G. A.; Metson, J. B. Phys. Chem. Chem. Phys. 2001, 3, 3838

60 L'Vov, B. V. Thermochim. Acta 1999, 13, 333.

61 Dallek, S.; Larrick, B. F.; West, W. A. J. Electrochem. Soc. 1986,133, 245.

62 Dodd, A.C.; Mckinley, A.J.; Saunders, M.; Tsuzuki, T. J. Nano. Research 2006, 8, 43. 
63 Bahnemann, D. Solar Energy 2004, 77, 445.

64 Jing, L.Q.; Qu, Y.; Wang, B.; Li, S.; Jiang, B.; Yang, L.; Wei, F.; Fu, H. J. Sun, Solar Ener. Mater. Solar Cells 2006, 90, 1773

65 Zhou, Z.; Quian, S.; Yao, S. Zhang, Z. Rad. Phys. Chem. 2002, 65, 241.

66 Zhao, J.; Wu,; Wu, T. K.; Oikawa, K.; Hidaka, H.; Serpon, N. Environ. Sci. Tech. 1998, 32, 2394.

67 Bandara, J.; Tennakone, K.; Binduhewa, P. New J. Chem. 2001, 25, 1302.

68 Liu, S.X.; Qu, Z.P.; Han, X. W.; Sun, C. L. Catalysis Today 2004, 93, 877.

69 Kamat, P.V. Pure Appl. Chem. 2002, 74, 1693.

70 Jakob, M.; Levanon, H.; Kamat, P.V. Nanoletters 2003, 3, 353. 